\title{
A poesia de Sá-Carneiro em diálogo com as artes plásticas surrealistas
}

Gustavo Henrique Rückert ${ }^{1}$

\begin{abstract}
The complex context of the early twentieth century, with all the technical innovations, urban development and international conflict brought profound disruptions to modern man. The identity that was once stable, focused and well-defined fragmented with a new way of life. In this context, the vanguard arts problematized the self representation, the representation of other and the representation of objects. These symptoms were present in different European contexts. Thus, this work intends to analyze Mário de Sá-Carneiro's poetry in dialog with surrealist art. The poem 16, by the Portuguese poet, and the painted Dream caused by the flight of a bee around a pomegranate a second before awakening, by the Spanish painter Salvador Dali, will be discussed. Elements like the dream, the dispersion of reality and the failure of representation are common to the works, showing that Sá-Carneiro introduced innovative elements in Portugal, which would be used by the surrealist movement some years after his death.
\end{abstract}

Keywords: Sá-Carneiro; vanguards; surrealism.

Resumo: O complexo contexto do início do século XX, com todas as inovações técnicas, o desenvolvimento urbano e os conflitos internacionais, trouxe profundas rupturas ao homem moderno. A identidade antes estável, centrada e bem definida fragmentou-se com um novo modo de vida. Nesse contexto, as artes de vanguarda problematizaram a questão da representação, seja de si, do outro ou dos objetos. Estando esses sintomas presentes em diversos contextos europeus, este trabalho pretende analisar o diálogo da poesia de Mário de Sá-Carneiro e das artes plásticas surrealistas. Do poeta português, será analisado o poema 16. Do movimento de vanguarda, a tela Sonho causado pelo voo de uma abelha em redor de uma romã, um segundo antes de despertar, do pintor espanhol Salvador Dalí. Elementos como o sonho, a dispersão da realidade e a incapacidade de representação são comuns às obras, evidenciando que Sá-Carneiro introduziu elementos inovadores em Portugal, os quais seriam utilizados alguns anos depois de sua morte pelo movimento surrealista.

Palavras-chave: Sá-Carneiro; vanguardas; surrealismo.

(...)a minh'Alma só, que me explodiu de cor...

Bárbaro, Mário de Sá-Carneiro

1 Doutor em Letras pela UFRGS e docente da Universidade Federal do Pampa (RS) 


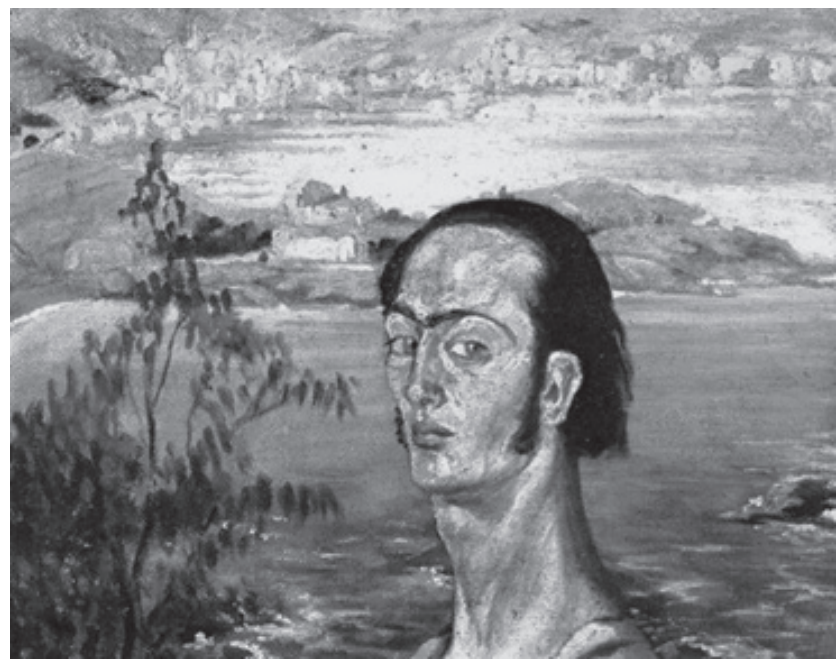

Salvador Dalí. Auto-retrato. 1921.

\section{Introdução}

Embora muitos críticos reduzam as vanguardas à arte de manifestos, encerradas em suas torres de marfim ao limitarem-se à metalinguagem, o entrecruzamento crítico e teórico dessas manifestações artísticas apresenta imensa riqueza cultural. As vanguardas são resultado da expressão de um homem modificado, que vê sua existência fragmentada em meio às traumáticas experiências do início do século XX e rompe com as representações humanistas do século XIX.

$\mathrm{O}$ acentuado desenvolvimento moderno da técnica, com todas as suas inovações e seu saber, conduziu à pior experiência da humanidade: a Grande Guerra. Os arranha-céus ruíram. O motor à combustão, a lâmpada, o telefone, o avião, blindados e metralhadoras revelaram o monstruoso desenvolvimento da técnica. O conhecimento era aplicado para acabar com um número nunca antes visto de vidas. Sem pena, sem compreensão, sem nada. Apenas estratégias para abarcar a maior quantidade possível de inimigos mortos.

Uma geração que ainda fora à escola num bonde puxado por cavalos viu-se abandonada, sem teto, numa paisagem diferente em tudo, exceto nas nuvens, e em cujo centro, num campo de forças de correntes e explosões destruidoras, estava o frágil e minúsculo corpo humano. (BENJAMIN, 1994, pg. 115)

A evidência da fragilidade da vida humana denunciava: era a derrota da Razão - agora apenas razão -, e o fim do sonho iluminista. Walter Benjamin (1994) explicou que a partir da ruptura com a antiga tradição nasceria uma nova estética. Antes, havia a sabedoria, que era baseada no acúmulo de experiência. Já no início do século, não se possuía nada. E é a partir disso que se formariam os novos artistas, bárbaros, segundo o teórico alemão. Eles questionariam o lógico, o claro, o tradicional. A força destruidora e impulsiva levaria ao escapismo, ao devaneio, ao inusitado, ao diferente. É claro que Benjamin se referia à arte vanguardista. E em linhas gerais "sua característica é uma desilusão radical com o século e ao mesmo tempo uma total fidelidade a esse século" (Benjamin, 1994, p.116). 
O poeta Fernando Pessoa, grande teórico do primeiro modernismo português, o Orphismo, ao analisar seu contexto, explica que o exagero dos avanços e suas facilidades, $\mathrm{o}$ caráter cosmopolita criado e a velocidade adquirida no início do século XX

criaram um tipo de civilização em que a emoção, a inteligência, a vontade, participam da rapidez da instabilidade e da violência das manifestações propriamente, diariamente, típicas do estádio civilizacional. (PESSOA, 1986, p. 436).

E estando as vertiginosas alterações desses tempos cotidianamente presentes na vida social, "em cada homem moderno há um neurastênico", "a tensão nervosa tornou-se um estado normal (...)" e "a hiperexcitação passou a ser regra" (PESSOA, 1986, p. 436). O português notava a falência da moral familiar nessa singular época, em que o homem "nascia doente da própria complexidade" (PESSOA, 1986, p. 437). Ele se voltava para a individualidade, negando uma sociedade em declínio. O gênio português acabou chegando na mesma questão de Benjamin, a arte de vanguarda deveria, ao mesmo tempo, negar essa modernidade e ser fiel a ela. E questionou: "como interpretar essa época, opondo-se-lhe?" (PESSOA, 1986, p. 438). A resposta, por ele mesmo expressa, trazia duas possibilidades: ou "fazer por vibrar com toda a beleza do contemporâneo" ou "cultivar serenamente o sentimento decadente" (Ibid.). A primeira das opções, em outras palavras, é a de ser um bárbaro, no sentido definido por Benjamin.

Esse sujeito oriundo dos novos paradigmas trazidos pelo século XX, por sua experiência traumática e fragmentada, acaba por romper com a identidade e as formas de representação unas, estáveis e centradas do sujeito do Iluminismo (Cogito, ergo sum). O bárbaro, como é definido por Benjamin, inserido numa nova noção do seu espaço e numa nova concepção do próprio tempo, acabou por representar-se e representar esse novo, tumultuado e opressor cenário em formas artísticas que buscaram romper com os conceitos tradicionais de Arte. Surgiram assim, as narrativas por fluxos de James Joyce, de Marcel Proust e de Virginia Woolf, a música composta pela desarmônica união de sons dissonantes de Stravinski, as pinturas que, em explosão de cores e traços, criavam realidades à parte nas próprias telas de cubistas, surrealistas, simultaneístas, expressionistas, impressionistas, etc. Por fim, os poemas também oriundos de experimentalismos das vanguardas buscaram romper com elementos tradicionais do gênero lírico clássico e logo passaram a ser incorporados em movimentos literários modernistas.

\section{Sá-Carneiro, um bárbaro moderno}

"Patch-work de romântico, futurista, expressionista, decadente, simbolista, cubista" (apud SÁ-CARNEIRO, 1996, p. 12), como definiu Fernando Cabral Martins, e deveríamos acrescentar ainda, sensacionista, é Mário de Sá-Carneiro. Sua poética abarca a ruptura da tradição lírica de um sujeito centrado, de identidade estável, e evidencia a crise identitária do sujeito moderno.

Síntese do ideal estético do grupo Orpheu, a corrente de vanguarda denominada sensacionismo, teorizada por Fernando Pessoa a partir de seu diálogo com Sá-Carneiro, defende que "não existe a realidade, apenas existem sensações" (PESSOA, 1986, p. 441). O programa dessa vanguarda portuguesa consiste basicamente em não ter programa, já que ela não está assentada sobre nenhuma base. Procura não romper com nenhuma escola estética também. Aceita contribuições de todas elas, desde que nunca se restrinja a nenhuma e prevaleça sempre a sensação.

Assim, Sá-Carneiro revela-se o grande realizador prático da proposta vanguardista teorizada por seu amigo Fernando Pessoa. Se na poesia de Pessoa havia uma genialidade extremamente 


\section{Conexão Letras}

racional e categorizante, que inclusive criara diversas personalidades literárias para, de forma organizada e esquemática, realizar por diferentes concepções estéticas a máxima da sensação, em Sá-Carneiro havia o ímpeto do sentimento não racionalizado pelo pensamento. Pessoa representou a fragmentação que vivenciava o sujeito moderno por meio do "um só em muitos"; já Sá-Carneiro, por meio do "muitos em um só”. Dessa maneira, o sujeito-lírico de Sá-Carneiro sente, imensa, intensa e inconsequentemente, por meio de cores, formas, aromas, sabores, estruturas poéticas mais tradicionais e mais inovadoras, nunca conseguindo concluir a associação identitária entre as coisas (sobretudo ele mesmo) e a linguagem. Para Lópes e Saraiva,

Há uma exuberância de imagens em que se traduzem, por vezes, as dimensões de uma alma intensamente vibrátil, capaz de multiplicar-se e identificar-se com as coisas e as pessoas; mas são sensíveis as limitações de uma megalomania egolátrica: a primeira pessoa verbal tornase obsessiva, a tortura das construções e metáforas, a acumulação orgiástica de sinestesias traem esforços falhados e o esgotamento narcísico de qualquer simpatia irradiante. (LÓPES; SARAIVA, 2005, p. 996)

Postado na Paris do início do século XX, Sá-Carneiro viveu o clima e a movimentação cultural do surgimento de inúmeras vanguardas e os precedentes de tantas outras. N e s s e intenso movimento cultural, muito conviveu com diversas manifestações artísticas e esteve envolvido por uma atmosfera que exigia mudanças nas formas de pensar e de representar. Essa complexidade intertextual e contextual resulta, mesmo que de modo inconsciente, em marcas no fazer literário. "Todo texto é a absorção e transformação de outro texto", diria Kristeva (1974, p. 64). Talvez de muitos outros textos. Assim, diálogos artísticos se deram de modo complexo e nem um pouco estanque na poesia de Sá-Carneiro. É nesse sentido que podemos perceber elementos que evidenciam o diálogo de sua obra com algumas das propostas futuristas, surrealistas, cubistas, dadaístas (mesmo que não tenha pertencido assumidamente a nenhum desses movimentos de vanguarda), porém sem negar as tradições já consolidadas do romantismo e do simbolismo portugueses. É por esse motivo que Cleonice Berardinelli (apud SÁ-CARNEIRO, 1991, p. 5) e Clara Rocha (1985, p. 27) afirmam ter sido o poeta precursor do surrealismo em Portugal, ao passo que João Gaspar Simões discorda veementemente dessa colocação (Cf. CARVALHO, 1967, p. 174).

Desse modo, pretendemos menos entrar na polêmica acerca das classificações do poeta em movimentos de vanguarda (o que seria, inclusive, contraditório se considerarmos a questão identitária de sua obra) que analisar o diálogo de elementos artísticos entre seus poemas e tais movimentos. Assim, acreditando que a intertextualidade pode "designar a transposição de um sistema de signos noutro", como defende Kristeva (apud JENNY, 1979, p. 13), tencionamos compreender um pouco do diálogo da poesia do orphista português com a vanguarda surrealista.

Conforme anteriormente exposto, em Sá-Carneiro houve a fragmentação agonística de um eu. É como se a sua fragmentação não fosse assumida, diferentemente da de Pessoa. Na necessidade narcísica da sua descrição, buscava imagens capazes dessa autorrepresentação. Todavia, não conseguia se encontrar em qualquer imagem empregada. Em Dispersão, há essa constatação (SÁ-CARNEIRO, 1996, p. 20-23):

\section{Dispersão}

Perdi-me dentro de mim

Porque eu era labirinto

E hoje, quanto me sinto,

É com saudades de mim 
Passei pela minha vida

Um astro doido a sonhar.

$\mathrm{Na}$ ânsia de ultrapassar,

Nem dei pela minha vida...

Para mim é sempre ontem,

Não tenho amanhã nem hoje:

O tempo que aos outros foge

Cai sobre mim feito ontem.

(O Domingo de Paris

Lembra-me o desaparecido

Que sentia comovido

Os Domingos de Paris:

Porque um domingo é família,

É bem-estar, é singeleza,

$\mathrm{E}$ os que olham a beleza

Não têm bem-estar nem família).

O pobre moço das ânsias...

Tu, sim, tu eras alguém!

E foi por isso também

Que te abismaste nas ânsias.

A grande ave dourada

Bateu asas para os céus,

Mas fechou-as saciada

Ao ver que ganhava os céus.

Como se chora um amante,

Assim me choro a mim mesmo:

$\mathrm{Eu}$ fui amante inconstante

Que se traíu a si mesmo.

Não sinto o espaço que encerro

Nem as linhas que projecto:

Se me olho a um espelho, erro -

Não me acho no que projecto.

Regresso dentro de mim,

Mas nada me fala, nada!

Tenho a alma amortalhada,

Sequinha, dentro de mim.

Não perdi a minha alma,

Fiquei com ela, perdida.

Assim eu choro, da vida,

A morte da minha alma.

Saudosamente recordo

Uma gentil companheira

Que na minha vida inteira

Eu nunca vi... Mas recordo 
A sua boca doirada

E o seu corpo esmaecido,

Em um hálito perdido

Que vem na tarde doirada.

(As minhas grandes saudades

São do que nunca enlacei.

Ai, como eu tenho saudades

Dos sonhos que não sonhei!...)

E sinto que a minha morte -

Minha dispersão total -

Existe lá longe, ao norte,

Numa grande capital.

Vejo o meu último dia

Pintado em rolos de fumo,

E todo azul-de-agonia

Em sombra e além me sumo.

Ternura feita saudade,

Eu beijo as minhas mãos brancas...

Sou amor e piedade

Em face dessas mãos brancas...

Tristes mãos longas e lindas

Que eram feitas pra se dar...

Ninguém mas quis apertar...

Tristes mãos longas e lindas...

E tenho pena de mim,

Pobre menino ideal...

Que me faltou afinal?

Um elo? Um rastro?... Ai de mim!...

Desceu-me nalma o crepúsculo;

Eu fui alguém que passou.

Serei, mas já não me sou;

Não vivo, durmo o crepúsculo.

Álcool dum sono outonal

Me penetrou vagamente

A difundir-me dormente

Em uma bruma outonal.

Perdi a morte e a vida,

E, louco, não enlouqueço...

A hora foge vivida,

Eu sigo-a, mas permaneço...

Castelos desmantelados,

Leões alados sem juba... 
O eu-lírico faz de si espaço. No entanto, para Fernando Cabral Martins (MARTINS apud SÁ-CARNEIRO, 1996, p. 12), "é a representação do eu como lugar de representação". Lugar esse que nunca se completa, está sempre a ser completado, como um permanente devir identitário no qual o sujeito sempre sente saudades daquilo que já não se é.

Clara Rocha apresenta um levantamento das metáforas utilizadas nessa busca incessante, inquietante e sempre incompleta por definir-se que constitui a obra de Sá-Carneiro, denominando-as "imagens da frustração" (ROCHA, 1985, p. 12-13). Abaixo, há a transcrição de algumas dessas imagens selecionadas pela pesquisadora:

\author{
trapézios escangalhados \\ castelos desmantelados \\ leões alados sem juba \\ quebram-se espadas de ânsia \\ seu templo prestes a ruir sem deus \\ asa que se elancou mas não voou \\ templos aonde nunca pus um altar \\ rios que perdi sem os levar ao mar \\ ravinas / Que não ouso percorrer
}

Rocha (Ibid.) ainda marca essa falta de unicidade e a decepção decorrente dela no emprego de símbolos que se desmancham no ar ou em líquido: bruma, espuma, nuvens, espasmo, quimera, cinzas, ... e também nos referentes verbos: desfazer-se, desmantelar, diluir-se, resvalar,...

A desilusão do sujeito que se vê fragmentado, inapto ao mundo e exilado do real pareceu levar a uma atitude - desesperada é claro -, desprender-se de explicações, de raciocínios, apenas querer sentir uma existência paralela: o sonho. O poeta buscou desenfreadamente por sinestesias, constituindo uma atmosfera de devaneio e um clima letárgico que diferenciava da realidade. O empoderamento imagético de suas sensações pode ser herança de Rimbaud, entretanto a sobreposição dos sentidos num devaneio que questiona a logicidade é elemento das vanguardas do início do século XX, sobretudo o surrealismo. Embora a poesia de Sá-Carneiro tenha sido cronologicamente anterior ao movimento propriamente dito dessa vanguarda, que se estabelece de maneira consolidada na Europa na década de 1920 e em Portugal somente na década de 1940, muito depois de sua morte, alguns elementos em comum podem ser encontrados na lírica do poeta português, que poderíamos inclusive dizer surrealizante por alguns momentos.

O interesse pelos sonhos, pela associação de ideias, pelas obsessões, enfim, pela manifestação do inconsciente é herança da psicanálise freudiana e foi ampla fonte artística para as vanguardas modernas, sobretudo para André Breton, grande mentor do surrealismo e autor de seus primeiros manifestos.

O movimento buscou o inusitado e o impossível considerando-se tempo e espaço. Assim, almejou "a emancipação do homem, o homem fora da lógica, da razão, da inteligência crítica, fora da família, da pátria, da moral e da religião - o homem livre de suas relações psicológicas e culturais" (TELES, 2009, p. 215). A magia verbal dava suporte para a desenfreada imaginação que encontrava sua lógica no ilógico, no irracional, no incomum. Em um momento posterior, ocorreu a adaptação para a pintura, e as composições pictóricas deram sustentação ideal para os sentimentos criados pelo devaneio entre o sonho e a vigília.

A vida só parecia ser digna de ser vivida quando se dissolvia a fronteira entre o sono e a vigília, permitindo a passagem em massa de figuras ondulantes, e a linguagem só parecia autêntica quando o som e a imagem, a imagem e o som, se interpenetravam, com exatidão automática, de forma tão feliz que não sobrava a mínima fresta para inserir a pequena moeda a que chamamos "sentido". (BENJAMIN, 1994, p. 22) 


\section{Conexão Letras}

Criava-se assim "uma existência que basta a si mesma, em cada episódio, do modo mais simples e cômodo, e na qual um automóvel não pesa mais que um chapéu de palha, e uma fruta na árvore se arredonda como a gôndola de um balão" (BENJAMIN, 1994, p. 19). E essa outra existência da qual falava Benjamin - e tão facilmente pode ser encontrada na arte surrealista - nada mais era então do que a própria realidade à parte criada pela arte, sobretudo pela arte do sonho, característica principal da arte moderna para Pessoa (1973). Para ele, havia os planos interior e exterior (ao indivíduo) de sensações. O primeiro denominou filosófico; o segundo, científico. A arte deveria organizar uma terceira ordem de sensações, o abstrato. Esse terceiro plano deveria ser o do sentimento dos sonhos. Obedeceria a condições da realidade, porém fugiria dela por obedecer também à emoção. "A consciência de si como sendo a concretização abstrata da emoção (a concretização emotiva da abstração)" (PESSOA, 1986, p. 449) é uma das definições que resumem as qualidades do conceito de arte sensacionista e está em congruência com o que pretendia o movimento surrealista.

Sá-Carneiro, em carta a Pessoa, refletiu sobre essas concepções e explicou seu ideal estético:

Para mim basta-me a beleza - mesmo errada, fundamentalmente errada. Mas beleza: beleza retumbante de destaque e brilho, infinita de espelhos, convulsa de mil cores - muito verniz e muito ouro: teatro de magias e apoteoses com rodas de fogo e corpos nus. (SÁ-CARNEIRO, 1996, p. 18)

E a correspondência era fiel, o poeta do inter-sonho, da vontade de dormir, buscou o delírio de todas as cores, brilhos, perfumes, tecidos, sons, paladares. Sangram os sentidos do sujeito-lírico no seu mundo de sensações.



Salvador Dalí. Sonho causado pelo voo de uma abelha em redor de uma romã, um segundo antes de despertar. 1944 
Uma das figuras mais emblemáticas nas artes plásticas do século XX é a do pintor catalão Salvador Dalí. Em diálogo com importantes nomes da pintura (mas também das demais artes) vanguardista de sua época, desenvolveu uma forma bastante peculiar e extravagante de realizar essas propostas, sobretudo o surrealismo. Ao discutir sobre o tema com Breton, Dalí (In: Salvador Dalí: liquid desire, 2015) chegou a definir-se como o maior e mais autêntico expoente dessa vanguarda: "A única diferença entre mim e os surrealistas é que eu sou um surrealista".

O grande mestre da arte surrealista pintou, em 1944, a tela intitulada Sonho causado pelo voo de uma abelha em redor de uma romã, um segundo antes de despertar. De acordo com interpretação do próprio Dali (apud TUR, 2007, p. 79) em relação à associação de imagens do seu inconsciente, o ruído de uma abelha seria associado a uma picada, que, por sua vez, lembraria um dardo. O alvo da picada fora sua musa Gala, que desperta. A biologia criativa surge da romã reinventada. Mais distante, o elefante de Bernini carrega um obelisco com atributos papais. A nudez de Gala, a romã, sua sombra projetando um coração, a dupla de tigres e a projeção interior do tigre em um peixe criam uma atmosfera erótica na tela, que pulsa em cores vivas e fortes.

Refletindo mais atentamente à questão do sonho, pode-se refletir sobre a quem é atribuído o sonho. Caso seja à Gala (personagem da inusitada composição imagética), é interessante pensar na sobreposição entre os planos da realidade e do devaneio, já que seu sonho está interseccionado à realidade. E a personagem da tela sente ambos. Caso seja ao próprio Dali, a tela inteira se refere à manifestação de seu sonho. Assim, o artista tornase personagem de si, representando imageticamente o seu inconsciente por meio de uma vibrante, colorida, inusitada, violenta, erótica e pulsante associação de imagens.

No poema "16" (2003, p. 43), de Sá-Carneiro, também é possível observar a atmosfera de devaneio com a qual o sujeito-lírico compõe inusitadas imagens por meio de sua associação de ideias. Contrapõe assim a lógica, à semelhança da tela de Salvador Dali:

Esta inconstância de mim próprio em vibração

É que me há de transpôr às zonas intermédias,

E seguirei entre cristais de inquietação,

A retinir, a ondular... Soltas as rédeas,

Meus sonhos, leões de fogo e pasmo domados a tirar

A tôrre d'ouro que era o carro da minh'Alma,

Transviarão pelo deserto, muribundos de Luar-

E eu só me lembrarei num baloiçar de palma...

Nos oásis, depois, hão de se abismar gumes,

A atmosfera há de ser outra, noutros planos:

As rãs hão de coaxar-me em roucos tons humanos

Vomitando a minha carne que comeram entre estrumes...

$* * * * *$

Há sempre um grande Arco ao fundo dos meus olhos...

A cada passo a minha alma é outra cruz,

E o meu coração gira: é uma roda de cores...

Não sei aonde vou, nem vejo o que persigo...

Já não é o meu rastro o rastro d'oiro que ainda sigo...

Resvalo em pontes de gelatina e de bolôres...

Hoje, a luz para mim é sempre meia-luz... 
As mesas do Café endoideceram feitas ar...

Caiu-me agora um braço... Olha, lá vai ele a valsar

Vestido de casaca, nos salões do Vice-Rei...

(Subo por mim acima como por uma escada de corda,

E a minha Ânsia é um trapézio escangalhado...).

O sujeito-lírico, na constatação de sua incapacidade de definição identitária, inclusive pela percepção da intersecção dos planos do devaneio e da realidade, reivindica a existência de uma outra zona, a intermédia. Nesse outro espaço, dos sonhos, em que "a atmosfera há de ser outra, noutros planos", há a utilização da imagem dos leões de fogo para a representação de seus sonhos, que atravessarão o deserto da realidade. Assim como na tela de Dalí, há intensidade na representação do insconciente (mesmo que Sá-Carneiro não tivesse lido a teoria de Breton). É essa intensidade e vivacidade leonina, de fogo, que é capaz de levar ao oásis, como é definida a zona intermédia. Lá, o sujeito-lírico pode não mais ser o eu a quem perturba a oscilação: está disperso mesmo entre o estrume e o vômito das rãs. Não mais se é justamente por tanto se ser: rãs, dejetos, leões, fogo.

O coração gira uma roda de cores: sente-se de maneira eferscente. Por não ser se é intensamente. A ponte (que é capaz de levar ao outro lado: da realidade ou da alteridade) não é sólida, é de gelatina, e não mais é nova, está embolorada. A luz, que é capaz de revelar os objetos à visão, é apenas meia-luz: na mesma proporção em que revela vela. Assim o sujeito -lírico vai associando imagens que não compreende: não é nenhuma delas, mas também as é, todas juntas, por serem a manifestação de seu inconsciente. O ser é um conflito: as mesas, concretas, se dissolvem no ar, seu braço, uma parte de si, torna-se um outro, desprende-se e põe-se a bailar de modo independete. Há, por fim, a fuga do sonho, do devaneio, da impossibilidade identitária. Mas a escada que leva à unicidade e à realidade, não é estável: é uma escada de corda onde subir parece menos possível que a ânsia de querer subir.

$\mathrm{Na}$ verdade, a sobreposição de imagens livremente associadas em "16", bem como a criação de um terceiro plano - do sonho - uma existência intensa, enigmática, incompreensível, que questiona a racionalidade, porém está presente em nossa percepção, impossibilitando ao sujeito delimitar-se com clareza e exatidão (afinal jamais dominará seu inconsciente) são características que vieram a ser marcantes, alguns anos após a vida de Sá-Carneiro, nas obras de vanguarda surrealista. Eis o "Sonho causado pela inconstância do poeta em vibração, um segundo antes de despertar”, de Sá-Carneiro.

\section{Considerações finais}

O que se tem é, por fim, um patch-work de estilos e características. Assim como propôs Pessoa, a respeito da nova arte, mantendo sob grande característica o devaneio, o sonho e cantando as belezas dos novos tempos com a melancolia dos antigos. Tudo isso sob a égide das grandes inquietações vanguardistas. Mesmo porque a própria arte de vanguarda encontra algumas raízes no passado. Na poesia muito se herdou das imagens febris e delirantes de Rimbaud; na pintura, dos traços imprecisos e anti-realistas de Van Gogh; na música, no impacto das composições de um Bach. O que se buscou com as vanguardas foi a negação de uma verdade, de um estilo clássico e canônico e uma estética de um belo que já não servia para os novos tempos. Teve-se, inclusive, a incorporação de uma nova forma de arte, que rapidamente alcançou a preferência do público: o cinema, que passa a reproduzir o dinamismo moderno e a nova forma de tempo e pensamento. 
Ler uma poesia de Sá-Carneiro, com toda sua explosão da frustração de um sujeito fragmentado em cores, texturas, formas, sons, cheiros acaba sintetizando uma nova época e um novo estilo de arte cujo principal traço é a ruptura. É como se se observasse quadros delirantes de Dali, fragmentados como os de Picasso ao som de Stravinski, que busca a destruição da linha melódica e a soma de inusitadas partes resultando na composição. Ele questiona a verdade criada acerca do padrão harmônico e clássico de música assim como Sá-Carneiro, e todo o Orpheu, questionam o tradicional conceito de poesia.

Os poemas desse bárbaro português em meio ao "milagroso carrousel" parisiense, observando o girar de "actrizes, prostitutas, lésbicas, [cidadãos] de luxo entediados, representantes da proletarização maciça das metrópoles, criaturas obscuras e vulgares " sintetiza o sentimento de toda uma Europa perdida em ruínas, questionando o valor de uma vida e seu papel no mundo, fugindo da realidade e do pensamento em direção à sensação.

E quando sente saudades de si, talvez seja saudade de outrora em que havia unidade, em que havia um sujeito claramente definido. Saudades de quando se acreditava em verdade, e o homem era o seu detentor. Saudades de ter sido Deus... São os modernos bárbaros, contudo, que brincam de deus. Criam a arte - e uma nova arte -, a partir da própria pobreza característica de seu tempo.

Eis porque, o sensacionista, amigo e companheiro de Orpheu,Fernando Pessoa considerou Mário de Sá-Carneiro "gênio não só da arte mas da inovação nela" (PESSOA, 1986, p. 456).

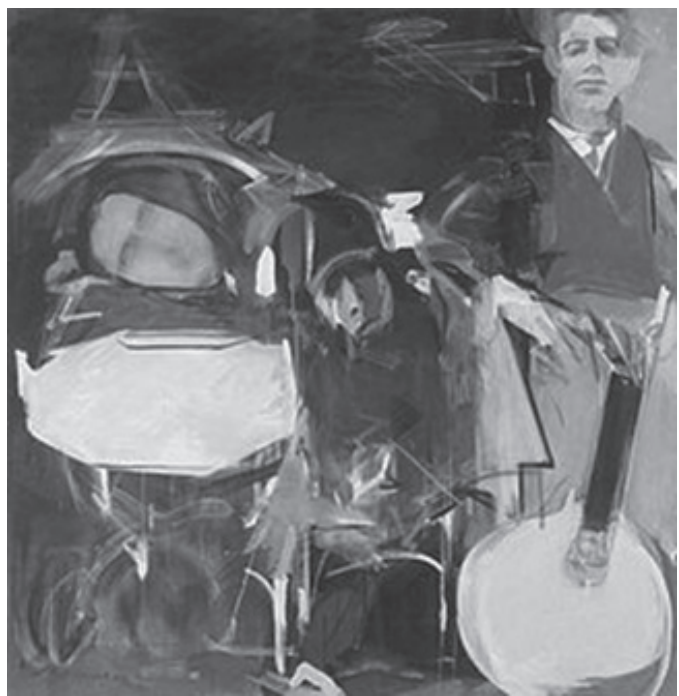

Júlio Pomar. Lusitânia no Bairro Latino - retratos de Mário de Sá Carneiro, Santa-Rita Pintor e Amadeo de Souza-Cardoso, 1985.

\section{Referências}

BENJAMIN, Walter. Magia e Técnica, Arte e Política. Trad. Sergio Paulo Rouanet. São Paulo: Brasiliense, 1994.

CARVALHO, Júlio. O estilo de Mário de Sá-Carneiro. In: $1^{o}$ simpósio de língua e literatura portuguesa. Rio de Janeiro: Gernasa, 1967. p.159-174. 


\section{Conexão Letras}

JENNY, Laurent. A estratégia da forma. Trad. Clara Crabbé Rocha. In: Poétique: Intertextualidades. $\mathrm{n}^{\circ}$ 27. Coimbra: Livraria Almedina, 1979. p. 5-49.

KRISTEVA, Julia. Introdução à semanálise. Trad. Lúcia Helena França Ferraz. São Paulo: Perspectiva, 1974.

LOPES, Oscar; SARAIVA, António José. História da Literatura Portuguesa. Porto: Porto Editora, 2005.

PESSOA, Fernando. A arte moderna é arte de sonho. In: PESSOA, Fernando. Páginas de Estética, Teoria e Crítica Literária. Lisboa: Ática, 1973. p.153-157. . Obras em prosa. Rio de Janeiro: Nova Aguilar, 1986.

ROCHA, Clara. O essencial sobre Mário de Sá-Carneiro. Lisboa: Imprensa Nacional, 1985. SÁ-CARNEIRO, Mário de. A confissão de Lúcio. Rio de Janeiro: Ediouro, 1991. . Poemas. Lisboa: Relógio d'água, 2003. . Poemas Completos. Lisboa: Assírio \& Alvim, 1996.

Salvador Dalí: liquid desire. A National Gallery of Victoria Education Resource. Disponível em: <. http://www.ngv.vic.gov.au/dali/salvador/resources/daliandsurrealism. pdf>. Acesso em: 09/07/2015.

TELES, Gilberto Mendonça. Vanguarda européia \& Modernismo brasileiro. Petrópolis: Vozes, 2009.

TUR, Juan-Ramón Triadó (cord.). Dalí. Coleção Gênios da Arte. Trad. Mathias de Abreu Lima Filho. Barueri: Girassol; Madri: Susaeta, 2007. 